\title{
Long-range transport of mineral dust observed with the Asian Dust and aerosol lidar observation Network (AD-Net)
}

\author{
Nobuo Sugimoto ${ }^{1, *}$, Atsushi Shimizu ${ }^{1}$, Tomoaki Nishizawa ${ }^{1}$, and Yoshitaka Jin $^{1}$ \\ ${ }^{1}$ National Institute for Environmental Studies, 16-2 Onogawa, Tsukuba, Ibaraki 305-8506 Japan
}

\begin{abstract}
AD-Net is an aerosol observation network using continuously operated multi-parameter lidars consists of 20 stations in East Asia. It is a "contributing network" of the WMO Global Atmosphere Watch (GAW) Program and is an Asian component of the GAW Aerosol Lidar Observation Network (GALION). The standard lidars in AD-Net are two-wavelength $(1064$ and $532 \mathrm{~nm})$ and polarization $(532 \mathrm{~nm})$ lidars, but multiwavelength Raman lidars and a multiwavelength high-spectral-resolution (532 nm) and Raman (355 $\mathrm{nm}$ ) lidar are also employed. The Mie scattering data from the AD-Net lidars are processed in near realtime (every hour) and published on the AD-Net www page in NetCDF format and graphical indications. AD-Net data are used in monitoring and various studies of Asian dust and regional air pollution. Analyses combining with chemical transport models showed that dust affecting the lower troposphere in Japan was mostly from the Gobi Desert, and dust from the Taklamakan was often transported in the free troposphere very long range. A case of Sahara dust transported through the Middle East and Central Asia was also found. Asian dust transported through polluted areas in East Asia is often internally mixed with air pollution. Results of studies using AD-Net lidars, in-situ polarization particle counters (POPCs), and sampling measurements of chemical composition are introduced.
\end{abstract}

\section{Introduction}

The continuous observation with an automatic Miescattering lidar started in 1996 in Tsukuba in a research program on long-term monitoring of aerosols related to global warming. A network observation was started in 2001 with three lidar stations (Tsukuba, Nagasaki and Beijing) in an Asian dust research project. The number of stations increased in various research projects and international cooperation programs. Currently, the network observation is conducted with 20 lidar stations in East Asia. The network was named "the Asian Dust and aerosol lidar observation Network (AD-Net)" and approved as a "contributing network" of the Global Atmosphere Watch (GAW) program of World Meteorological Organization (WMO) in 2008. AD-Net is also a component of GAW Aerosol Lidar Observation Network (GALION). The data from AD-Net are used in monitoring and studies of Asian dust and regional air pollution.

In this paper, we introduce AD-Net and the studies using AD-Net. We review the results of the studies on transport of mineral dust. Dust that affects the lower troposphere in East and Northeast China, Korea, and Japan is mostly generated in the Gobi Desert in Mongolia and Inner Mongolia of China. Dust from the Taklamakan desert is observed often in the free troposphere. In addition, dust from Africa, the Middle East, and Central Asia occasionally transported to East Asia. We introduce a case study of long-range transport of dust from the Sahara Desert through the Middle East and Central Asia to East Asia [1], which would be relevant to this conference. We also discuss change in optical characteristics of dust during transport. In the lower atmosphere in East Asia, internally mixed (polluted) dust is often observed.

\section{AD-Net}

\subsection{Lidar instruments, the network, and data products}

Figure 1 shows location of lidars in AD-Net. The lidars used at most AD-Net stations are two-wavelength (1064 and $532 \mathrm{~nm}$ ) and polarization $(532 \mathrm{~nm})$ lidars (AD-Net standard lidars). The lidar at several locations has an additional Raman receiver channel at $607 \mathrm{~nm}$. Multiwavelength Raman lidars are used in Fukuoka, Hedo and Toyama, and a multi-wavelength high-spectralresolution $(532 \mathrm{~nm})$ and Raman $(355 \mathrm{~nm})$ lidar is used in Tsukuba. Details of the lidar specifications are described in Reference [2]. Figure 2 shows a photograph of the AD-Net standard lidar. It is installed in a container having a glass window on the roof and operated continuously regardless of weather.

The observed data are transferred to the data center at National Institute for Environmental Studies (NIES) every hour and processed automatically (except for the cooperative stations in China, at present). The attenuated backscattering coefficient at $1064 \mathrm{~nm}$ and $532 \mathrm{~nm}$, the

\footnotetext{
* Corresponding author: nsugimot@nies.go.jp
} 
volume depolarization ratio at $532 \mathrm{~nm}$, and the extinction coefficient estimates for non-spherical and spherical aerosols (described in the following section) derived from Mie scattering signals are published on the AD-Net www page in NetCDF format and graphical indications in near realtime (updated every hour). An example of the graphical indications is shown in Fig. 3.

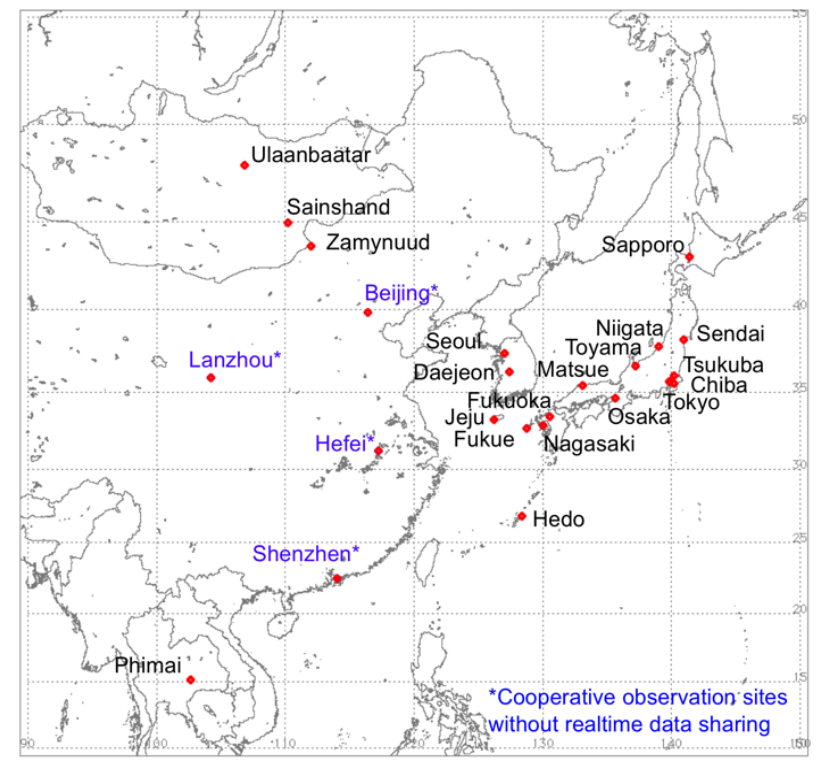

Fig. 1. Locations of the AD-Net lidars.

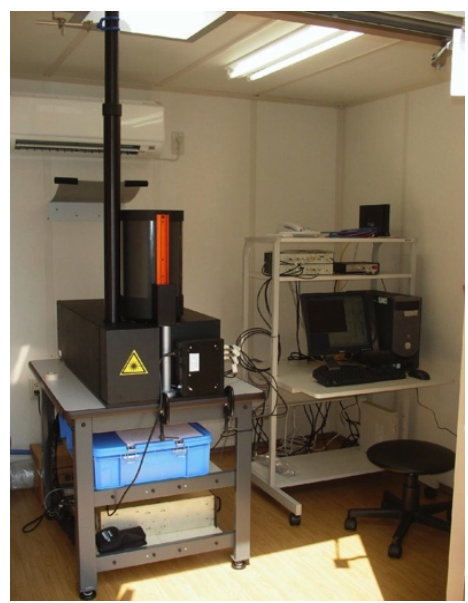

Fig. 2. Photograph of the AD-Net standard lidar.

\subsection{Data analysis methods for multi-parameter lidars}

A method for deriving extinction coefficient estimates for non-spherical and spherical aerosols from backscattering and depolarization ratio was developed for studying distribution of Asian dust [3, 4]. The method is based on an assumption that the observed aerosols are external mixture of two types of aerosols, namely non-spherical dust having a large particle depolarization ratio and spherical aerosols having a small particle depolarization ratio. The mixing ratio of the two types is determined so that the observed particle depolarization ratio is reproduced. The method uses the
Fernald backward inversion [5] with a constant extinction-to-backscattering ratio (lidar ratio, S1) and partitioning the types assuming the particle depolarization ratios values for two aerosol types. Though the method is based on these assumptions, it is practically useful for monitoring dust and air pollution events.

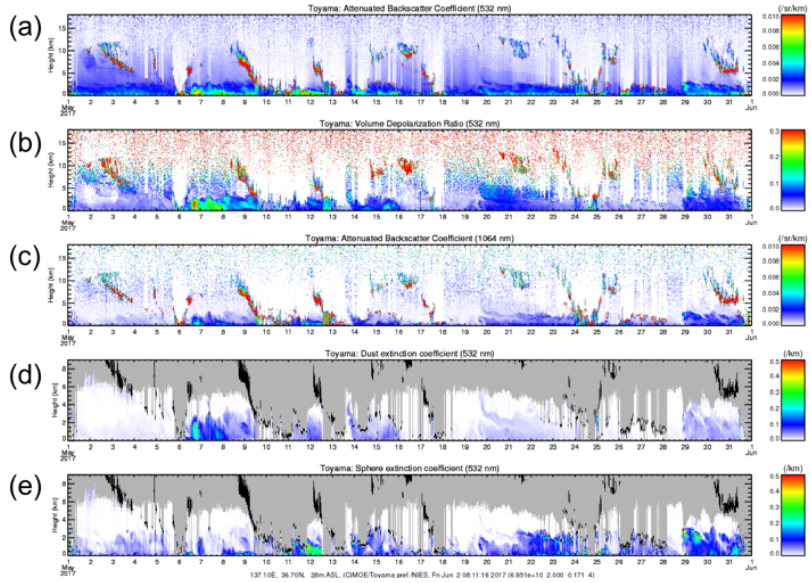

Fig. 3. Time-height-indications of (a) attenuated backscattering coefficient at $532 \mathrm{~nm}$, (b) volume depolarization ratio at 532 $\mathrm{nm}$, (c) attenuated backscattering coefficient at $1064 \mathrm{~nm},(\mathrm{~d})$ extinction coefficient estimate at $532 \mathrm{~nm}$ for non-spherical particles, and (e) extinction coefficient estimate at $532 \mathrm{~nm}$ for spherical particles, for Toyama, May 2017.

The concept of aerosol component analysis was introduced by Nishizawa, et. al. [6-9]. The analysis method is based on the assumptions of optical characteristics of aerosol components, and the concentrations of the aerosol components are determined so that the observed lidar signals are reproduced. The aerosol components that can be derived is dependent on the parameters measured with the lidars, as listed in Table 1. Here, $\alpha, \beta$, and $\delta$ represent extinction, backscattering, and depolarization. The number indicates the number of measured wavelengths.

Table 1. Aerosol components determined by the aerosol component analysis method.

\begin{tabular}{|c|l|}
\hline $\begin{array}{c}\text { Measured } \\
\text { parameters }\end{array}$ & Determined aerosol components \\
\hline $1 \beta+1 \delta$ & $\begin{array}{l}\text { non-spherical (dust) } \\
\text { spherical (sulfate, etc.) }\end{array}$ \\
\hline $2 \beta+1 \delta$ & $\begin{array}{l}\text { non-spherical (dust) } \\
\text { spherical fine (sulfate, etc.) } \\
\text { spherical coarse (sea salt) }\end{array}$ \\
\hline $1 \alpha^{\alpha}+2 \beta+1 \delta$ & $\begin{array}{l}\text { non-spherical (dust) } \\
\text { weak-absorption fine (sulfate, etc.) } \\
\text { weak-absorption coarse (sea salt) } \\
\text { strong-absorption fine (black carbon) }\end{array}$ \\
\hline $2 \alpha^{\alpha}+3 \beta+2 \delta$ & \multicolumn{2}{|l}{}
\end{tabular}

Figure 4 shows a result of the aerosol component analysis of multiwavelength Raman lidar data in 
Fukuoka from September 2014 to July 2017. Concentrations of four aerosol components were derived from extinction coefficient at $532 \mathrm{~nm}$, backscatter coefficient at $532 \mathrm{~nm}$ and $1064 \mathrm{~nm}$, and particle depolarization ratio at $532 \mathrm{~nm}$ [10]. Spheroid model [11] was used for dust in this work.

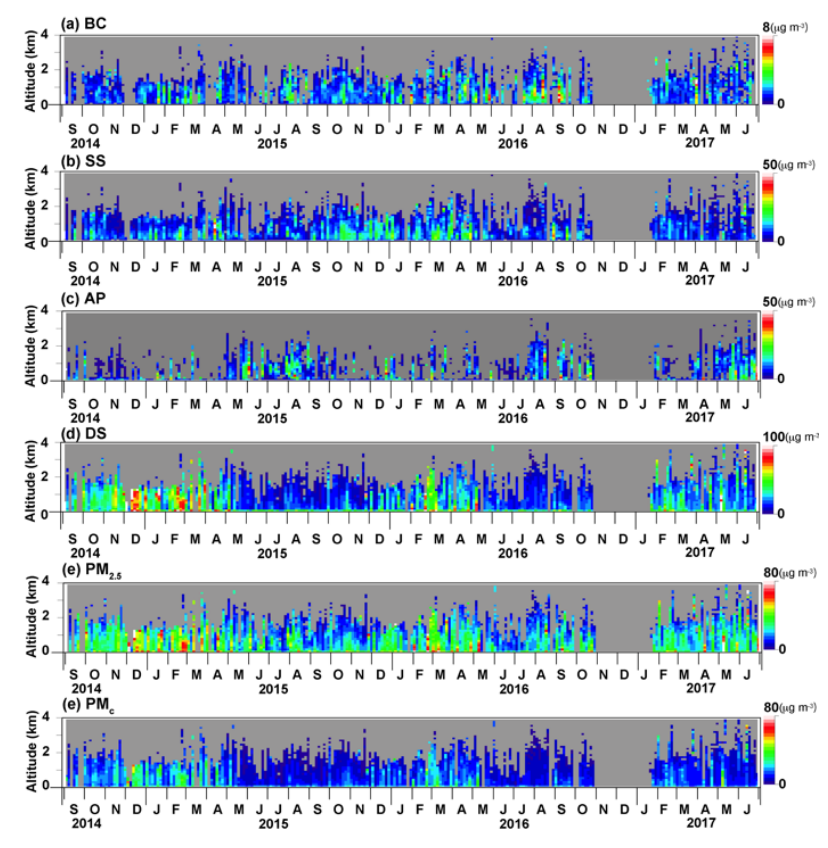

Fig. 4. Time-height cross section of lidar-derived aerosol mass concentration for (a) black carbon, (b) sea salt, (c), air pollution

(sulfate, etc.) (d) dust, (e) PM2.5, and (f) PM10-2.5 [10].

The result of the analysis was compared with surface mass concentration measurements of aerosol chemical compositions, and the optical models for aerosol components used in the analysis were evaluated. It was found that black carbon (BC) mass concentration derived from the lidar using a pure BC optical model was much overestimated, and it was drastically improved using a core-gray-shell BC model. In some cases, sea salt concentration was overestimated due to misclassification of internally mixed dust as sea salt $[10,12,13]$. The problem is discussed in Section 3.3.

\subsection{Studies using AD-Net data}

AD-Net data are used in various research on Asian dust and air pollution in East Asia. The realtime AD-Net data are also used on the dust information www page of Ministry of the Environment, Japan [14]. One of the most important subjects is validation and assimilation of chemical transport models. In most of the studies, we used the extinction coefficients for non-spherical and spherical particles, which are included in the standard AD-Net data products published on AD-Net www page. Though these products are based on the assumptions on lidar ratio and external mixing, we think it is reasonable to use non-spherical (dust) extinction coefficient for validation and assimilation of dust transport models, especially in the case the distributions of non-dust aerosols are not well reproduced with the model. Figure 5 explains the concept. The dust extinction coefficient can be compared directly with that calculated from chemical transport models.

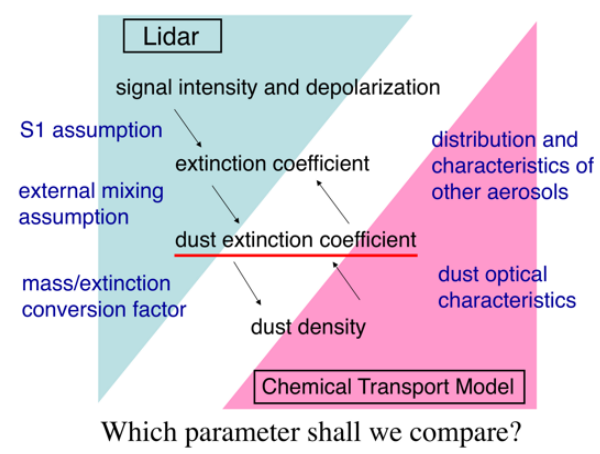

Fig. 5. Diagram explaining that using the dust extinction coefficient is reasonable when the errors in models and lidar data analysis are considered.

A 4D-Var data assimilation system for mineral dust was developed at Kyushu University based on the regional chemical transport model, CFORS $[15,16]$. The dust extinction coefficient was used as the parameter for data assimilation, and the emission factors for the grid points in the source area were the control parameters. It was demonstrated the assimilated model better reproduced dust distribution. It was also shown the data assimilation was useful for better estimating dust emission in source areas. The assimilated model was used for analysis of Asian dust events [17-19].

The dust and spherical extinction coefficients in the AD-Net data product are also used in climatological studies of Asian dust [20] and air pollution [2, 21]. A decreasing trend of air pollution aerosols is seen over Japan in recent several years reflecting the reduction of emission in China. A decreasing trend is also seen in Asian dust [20]. The trend is larger in higher altitude over Japan, and the trend is not significant in the source region in Mongolia. That suggests change in meteorology related to dust transport in recent years.

AD-Net data are also used in epidemiology of the effect of Asian dust and air pollution aerosols on human health $[22,23]$. It is shown that the lidar-derived dust extinction coefficient is useful because there are no insitu instruments that can provide dust concentration in realtime, except for the polarization particle counter (POPC) [24].

\section{Transport of mineral dust revealed by AD-Net}

\subsection{Dust from the Gobi and the Taklamakan desert}

Analysis combining AD-Net observations and the chemical transport model, CFORS revealed the dust emission source of heavy dust events affecting the lower troposphere in Japan is the Gobi Desert in Mongolia and Inner Mongolia in China. In large dust events, dust is transported in the boundary layer behind a cold front up to Japan [3]. In Beijing, heavy air pollution is often 
observed before a dust event. A low pressure locates in the west of Beijing before the dust event, and heavily polluted air is transported from the south where industrial areas are located. As the low pressure moves east, strong wind with dust blows from the north west. Dust is mixed with air pollution and transported east [3].

A statistical analysis showed the fraction of elevated dust layer increases as the distance from the source area increases [4]. The mechanism of forming elevated dust layer was recently studied by Kawai et al. [25]. Cases of entrainment of elevated dust layer into the convective mixing layer were also observed with the lidars [26].

Dust from the Taklamakan Desert is often lifted to the free troposphere and transported long range because of the geographical situation surrounded with mountains. Uno et al. (2009) showed a Taklamakan dust case transported full circle in 13 days around the globe using the data of the spaceborne lidar CALIPSO/CALIOP and a global chemical transport model [27].

\subsection{Long-range transport from the Sahara to East Asia}

A long-range transported Saharan dust case was observed in March 2005 in Suwon ( 30 km south of Seoul) and Gosan (Jeju), Korea and Tsukuba, Japan. Time-height indications of range-corrected backscatter signal and volume depolarization ratio are shown in Fig. $6[1]$.

\section{(a) Suwon}

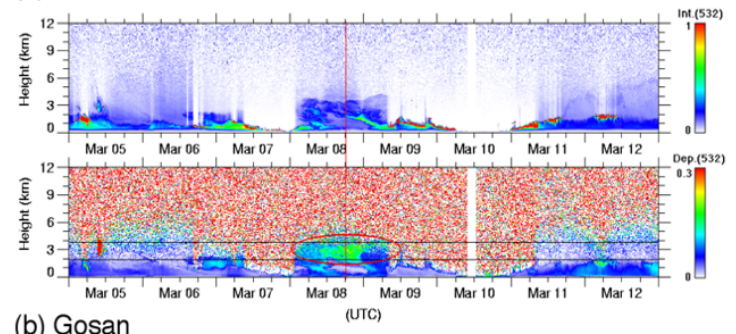

(b) Gosan

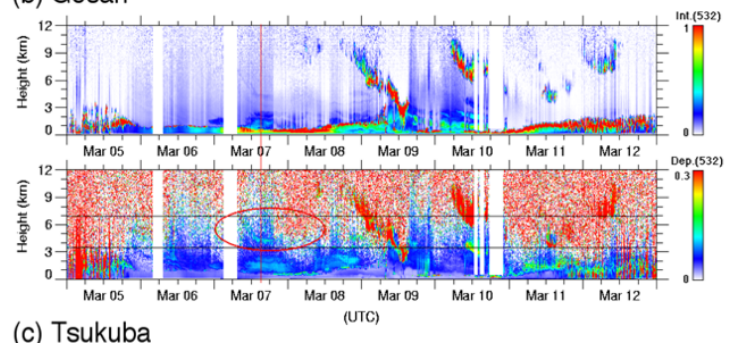

(c) Tsukuba

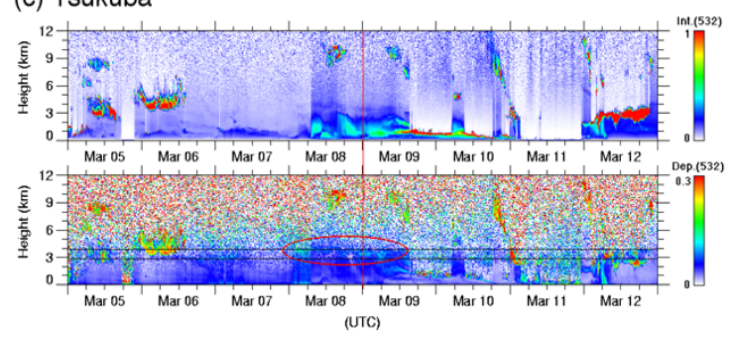

Fig. 6. THIs of the lidar range-corrected backscatter signal and total depolarization ratio at $532 \mathrm{~nm}$ observed in (a) Suwon, (b) Gosan, and (c) Tsukuba in March 5-12, 2005 [1].
The high depolarization ratio areas marked with red circles are the dust from the Sahara Desert. The extinction coefficient estimated at the laminar plumes in Gosan and Tsukuba was about $0.05 \mathrm{~km}^{-1}$, and estimated mass concentration was about 25-75 $\mu \mathrm{g} \mathrm{m}^{3}$.

The global chemical transport models NAAPS [28] and SPRINTARS [29] predicted the dust plume as shown in Fig. 7 (Supplement 2 of Ref. [1]).

(A) NAAPS

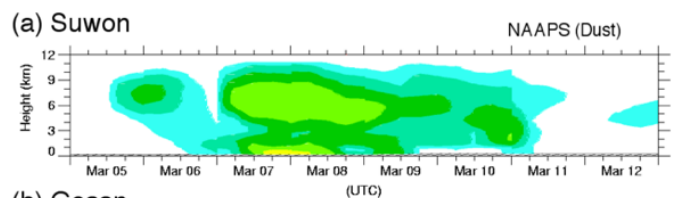

(b) Gosan NAAPS (Dust)

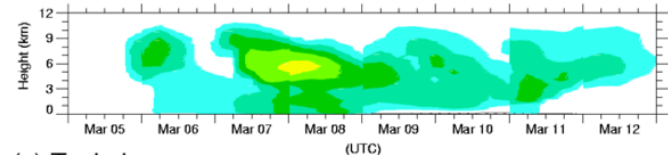

(c) Tsukuba

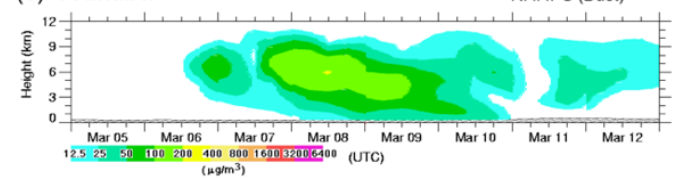

(B) SPRINTARS

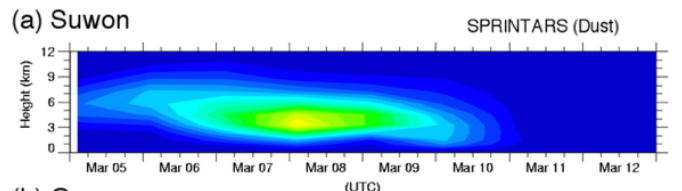

(b) Gosan SPRINTARS (Dust)
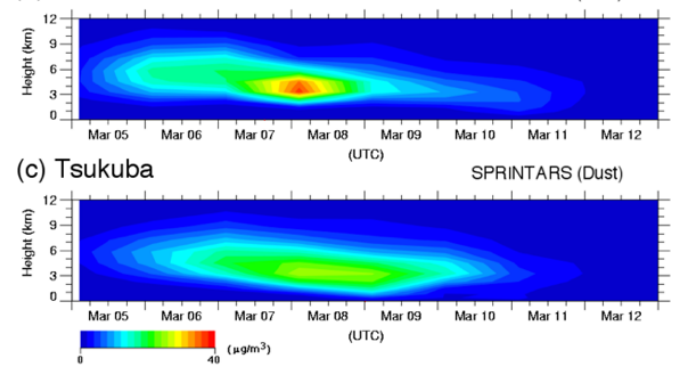

Fig. 7. Time-height indications of dust concentration at Suwon, Gosan, and Tsukuba calculated with (A) NAAPS and (B) SPRINTARS.

The origin of the dust was investigated with a retrospective NAAPS simulation separately masking Sahara and Taklimakan dust sources beginning on February 24, 2005. A comparison of this simulation with the operational run shows that the dust above $3 \mathrm{~km}$ seen Fig. 7(A) is of Saharan origin. NAAPS simulated dust events on Feb 25-27, Feb 28-Mar 2, and Mar 3-6 in the Sahara Desert. The dust from the first event takes 10 days to reach East Asia, the second is quicker, about 6 days. The third one is not transported to East Asia. The SPRINTARS dust column loading map also shows the source of the dust was the Sahara Desert [1].

In order to confirm the transport paths of the dust observed in Suwon, Gosan, and Tsukuba, the backward trajectories are calculated with the NOAA HYSPLIT model [30]. Figure 8 shows the results [1]. The 
backward trajectory for the laminar plume observed in Gosan at 15:00 of March 7 clearly shows the origin is Sahara, and the dust was transported in 5-6 days. The backward trajectory for Tsukuba at 00:00 March 9 also shows the laminar plume was from Sahara, and the transport time was 8-9 days. The results are consistent with the NAAPS simulation. The transport path was similar to that in the Middle East dust case in 2003 reported in Refs. [31, 32].

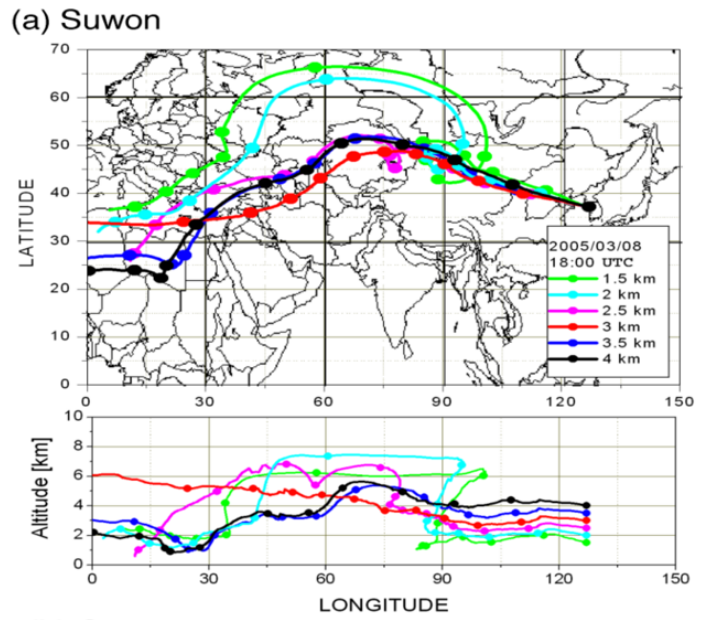

(b) Gosan
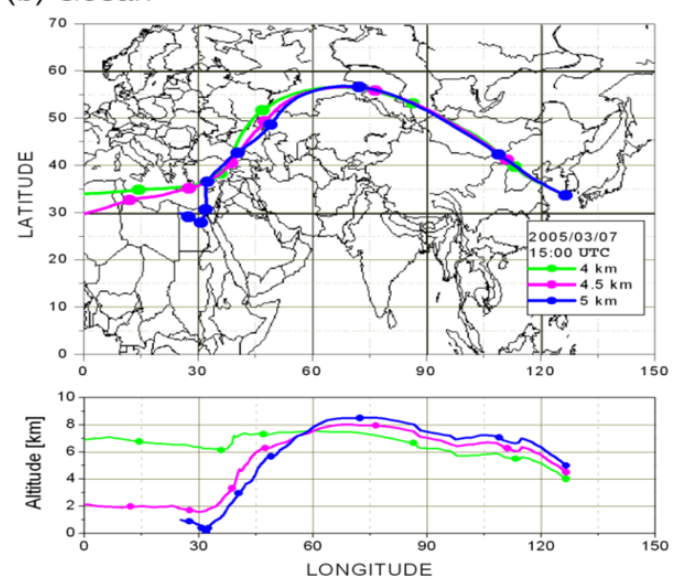

(c) Tsukuba
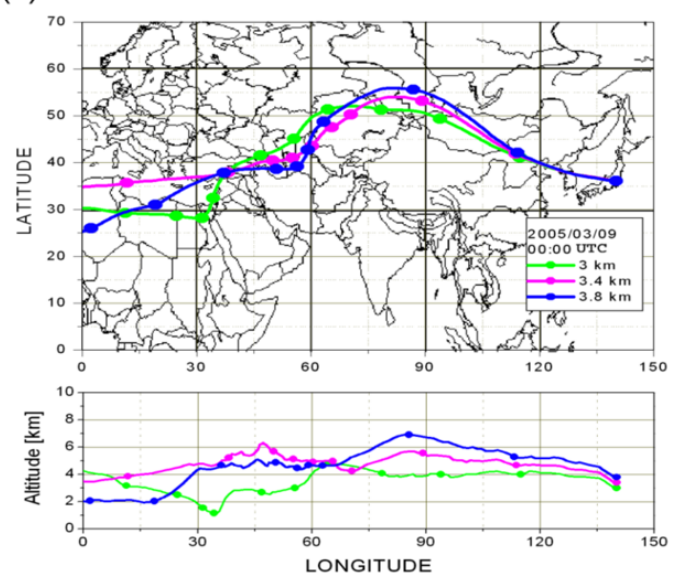

Fig. 8. HYSPLIT backward trajectories from (a) Suwon (March 8, 15:00), (b) Gosan (March 7, 15:00) and (c) Tsukuba (March 9, 00:00). The circles on the paths indicate the period of one day [1].
Though we haven't analysed recent data yet on longrange transport from Africa, the Middle East, and Central Asia to East Asia, it would be a subject of interest to study using ground-based lidars, spaceborne lidars, and chemical transport models. The concentration of the long-range transported dust may not be high, but it could be significant in the transport of bioaerosols, for example.

\subsection{Change in optical characteristic of mineral dust during transport}

The optical characteristics of mineral dust change during transport. One cause is the change in size distribution due to gravity settling. Another cause is the change in morphology or surface characteristics due to internal mixing or heterogeneous reaction. Generally, the particle depolarization ratio decreases as transported in both cases.

In East Asia, mineral dust is often transported through heavily polluted area, and interaction of dust and air pollution is important. Asian dust plume with a low particle depolarization ratio was observed in the Western Pacific, and external and internal mixing of mineral dust and air pollution aerosols was discussed using a diagram of the particle depolarization ratio versus the backscattering wavelength ratio [33]. Later, it was discussed clearer using the lidar in Seoul comparing with the simultaneous POPC measurements [12].

Figure 9 shows the diagram for the observations in Seoul for air pollution aerosol (April 13, 2013), Pure dust (April 14), and internally mixed (polluted) dust (April 30) [12]. Polluted dust can be distinguished from external mixture. In the external mixing case, both depolarization ratio and color ratio decrease, and the data points fall on the line connecting pure dust and air pollution cases. In the internal mixing case, depolarization ratio decreases, but color ratio doesn't change much. (However, if we also consider sea salt having a low depolarization ratio and a high color ratio, the polluted dust may be interpreted as external mixture of dust and sea salt.)

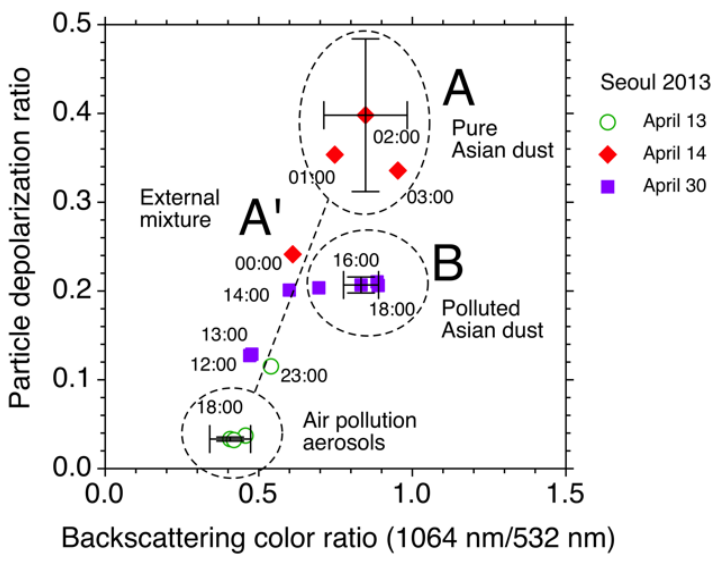

Fig. 9. Scatter diagram between the lidar color ratio (1064 nm/ $532 \mathrm{~nm}$ ) and the particle depolarization ratio at $532 \mathrm{~nm}$ [12]. 
In-situ POPC can measure particle size and depolarization ratio of single particles. It is essentially different from the volume measurements with lidars. In the scattering diagram between the depolarization ratio and particle size, distributions of data points for different types of particles are separated, and external mixing and internal mixing are clearly distinguished [12].

Simultaneous measurements of particle composition and optical characteristics (POPC and lidar) were performed in a long-lasting dust event in Beijing in March-April 2015. Observed data are analysed with a chemical transport model including heterogeneous reactions. [13, 34] Figure 10 shows time-height indications of the spherical and non-spherical (dust) extinction coefficients observed with the lidar in Beijing and calculated with the model [34]. (In this lidar plot, internal mixing is not distinguished with external mixing. However, coexistence of dust and air pollution can be identified.)

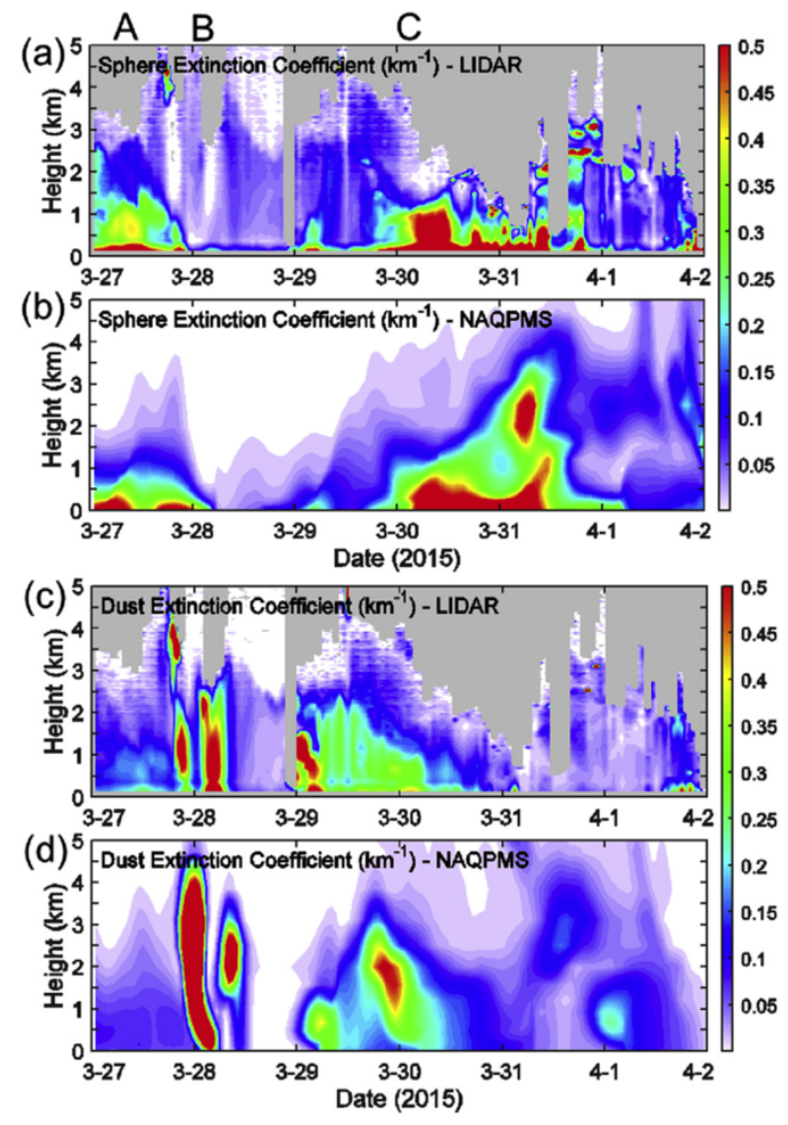

Fig. 10. Lidar-observed $(a, c)$ and model-simulated (b, d) timeheight indications of anthropogenic $(a, b)$ and dust $(c, d)$ extinction coefficients in Beijing [34].

Three high extinction coefficient cases A, B, and C were defined using the lidar plot in Fig. 10. A is air pollution case, $\mathrm{B}$ is pure dust case, and $\mathrm{c}$ is mixing case. Figure 11 shows the POPC scattering diagram for the three cases and the observed and simulated chemical compositions for Case $\mathrm{C}$. The clear difference can be seen in the POPC scatter diagram between air pollution, pure dust, and internally mixed dust. In internal mixing case, Case $\mathrm{C}$, the depolarization ratio of dust decreased.
The results of the observation and the simulation showed heterogeneous reaction with nitrate was significant. Also, a theoretical study of optical characteristics of dust particle showed the change in morphology is the major cause of the decrease of depolarization ratio [13].
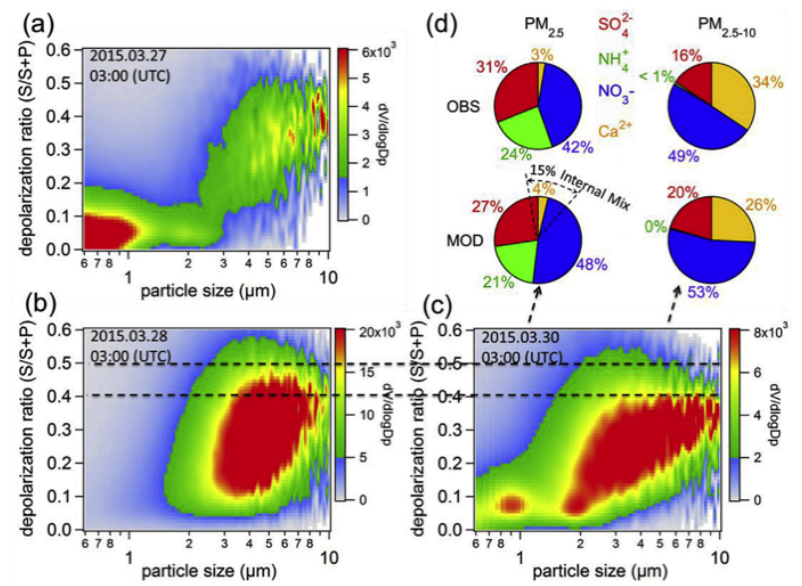

Fig. 11. Volume concentrations of different particle sizes and depolarization ratios during (a) air pollution, (b) pure dust, and (c) mixed dust-pollution episodes in Beijing. (d) Observed (up) and simulated (bottom) mass fractions of sulfate (red), nitrate (blue), ammonium (green), and calcium (yellow) ions relative to the total principal water-soluble ions in PM2.5 (left) and PM2.5-10 (right) during the mixed dust episode [34]. (Note: The depolarization ratio was measured at a scattering angle of 120 degrees in POPC.)

Change in optical characteristics of dust in the free troposphere like that described in Section 3.2 would be caused mostly by the change in particle size distribution. Measurements with ground-based multiparameter lidars (multiwavelength Raman lidars, multiwavelength highspectral-resolution lidars (HSRLs)) and sun photometers (sky radiometers) along the transport path would be useful for the study.

\section{Outlook of AD-Net}

AD-Net plays an important role as a regional network for monitoring Asian dust and air pollution. At the same time, it contributes to long-term monitoring of the global atmosphere as a "contributing network" of GAW and an Asian component of GALION. The requirement for observations is different for regional and global monitoring in temporal spatial resolution and accuracy of the measurements. In the global monitoring, observations up to higher altitude with a higher accuracy are required. In the regional monitoring, continuous operation and realtime data processing are essential.

We have improved the lidars in AD-Net considering the requirements. Currently we have three multiwavelength Raman lidars and one HSRL in the network. All lidars are operated continuously. We are currently developing a multiwavelength HSRL using a scanning interferometer. It employs a single-mode laser and the idea of scanning interferometer introduced in the study of multi-mode HSRL [35]. We are also considering the 
use of simpler lidars, ceilometers, at remote site in the network [36].

The current AD-Net stations are located so that all dust events and regional air pollution transported to Japan are captured without missing. For understanding dust phenomena in the Gobi and Taklamakan totally, more stations are required especially in China. Also, it would be useful to have a network in the Middle East and Central Asia, along the dust transport pass to East Asia. As for biomass burning and forest fire, more stations are required in South East Asia and in the Far East Russia. We would seek more possibility of international cooperation.

In both regional and global aerosol monitoring, it is essential to cooperate with modelling studies. For validating dust transport models, we think it is reasonable to use the dust extinction coefficient estimated from polarization lidars as explained in Section 2.3 (Fig. 5). We may also use the dust extinction coefficient (not mass concentration) determined with the aerosol component analysis method.

The current aerosol component analysis method cannot handle internal mixing between components. The lidar ratio for internally mixed dust must be different from external mixture of dust and sea salt. However, it would be difficult to separate them in the mixture of dust, air pollution aerosols, and sea salt, considering the measurement errors and/or the variability in the measured values themselves. If it is known that there is no sea salt, or the concentration of sea salt is known, some estimate of internally mixed (polluted) dust can be derived. Consequently, an analysis considering spatial distribution of aerosol components would be useful. Data assimilation based on a chemical transport model including internal mixing can be a solution.

It is also important to understand microphysical characteristics of pure dust and refine the optical model for dust. Size distribution, shape, and wavelength dependent complex refractive index are essential. They are dependent on the source region, and they change during transport. Accurate observations with networks of multiparameter lidars and sun photometers (sky radiometers) are useful.

In the validation and assimilation of the aerosol prediction models which aim at accurate prediction of all types of aerosols, we need a more consistent approach for using backscattering lidar data. We think the use of the extinction coefficient derived with modeled lidar ratio profile is the most reasonable method for backscattering lidars [37]. There are many different types of lidars in GALION, and we think it would be very useful to develop a data processing system that can be applied to all lidars to use the data for validation/assimilation of aerosol prediction models.

\section{References}

1. C.-B. Park, N. Sugimoto, I. Matsui, A. Shimizu, B. Tatarov, A. Kamei, C.-H. Lee, I. Uno, T. Takemura, D. L. Westphal, SOLA 1, 121 (2005)
2. A. Shimizu, T. Nishizawa, Y. Jin, S.-W. Kim, Z. Wang, D. Batdorj, N. Sugimoto, Opt. Eng. 56 (3), 031219 (2017)

3. N. Sugimoto, I. Uno, M. Nishikawa, A. Shimizu, I. Matsui, X. Dong, Y. Chen, H. Quan, Geophys. Res. Lett. 30 (12), 1640 (2003)

4. A. Shimizu, N. Sugimoto, I. Matsui, K. Arao, I. Uno, T. Murayama, N. Kagawa, K. Aoki, A. Uchiyama, A. Yamazaki, J. Geophys. Res. 109, D19S 17 (2004)

5. F. G. Fernald, Appl. Opt. 23, 652 (1984)

6. T. Nishizawa, H. Okamoto, N. Sugimoto, I. Matsui, A. Shimizu, K. Aoki, J. Geophys. Res., 112, D06212 (2007)

7. T. Nishizawa, N. Sugimoto, I. Matsui, A. Shimizu, B. Tatarov, H. Okamoto, IEEE Trans. Geosci. Remote Sens. 46, 4094 (2008)

8. T. Nishizawa, N. Sugimoto, I. Matsui, A. Shimizu, H. Okamoto, J. Quanti. Spectrosc. Radiat. Transf. 112254 (2010)

9. T. Nishizawa N. Sugimoto, I. Matsui, A. Shimizu, Y. Hara, U. Itsushi, K. Yasunaga, R. Kudo, S.-W. Kim, J. Quant. Spectrosc. Radiat. Transf. 188, 79 (2017)

10. Y. Hara, T. Nishizawa, N. Sugimoto, K. Osada, K. Yumimoto, I. Uno, R. Kudo, H. Ishimoto, Remote Sens. 10, 937 (2018)

11. O. Dubovik, A. Sinyuk, T. Lapyonok, B. N. Holben, M. Mishchenko, P. Yang, T. F. Eck, H. Volten, O. Muñoz, B. Veihelmann, et al., J. Geophys. Res. 111, D11208 (2006)

12. N. Sugimoto, T. Nishizawa, A. Shimizu, I. Matsui, H. Kobayashi, J. Quant. Spectrosc. Radat. Trans. 150,107 (2015)

13. X. Pan, I. Uno, Z. Wang, T. Nishizawa, N. Sugimoto, S. Yamamoto, H. Kobayashi, Y. Sun, P. Fu, X. Tang, Z. Wang, Sci. Rep. 7, 335 (2017).

14. MOEJ Real-time DSS Information www page, http://www2.env.go.jp/dss/kosa/en/index.html (last access: September 2018)

15. K. Yumimoto, I. Uno, N. Sugimoto, A. Shimizu, S. Satake, Geophys. Res. Lett. 34, L08806 (2007)

16. K. Yumimoto, I. Uno, N. Sugimoto, A. Shimizu, Z. Liu, D. M. Winker, Atmos. Chem. Phys. 8, 2869 (2008)

17. Y. Hara, K. Yumimoto, I. Uno, A. Shimizu, N. Sugimoto, Z. Liu, D. M. Winker, Atmos. Chem. Phys. 9, 1227 (2009)

18. N. Sugimoto, Y. Hara, K. Yumimoto, I. Uno, M. Nishikawa, J. Dulam, SOLA 6, 125 (2010)

19. N. Sugimoto, Y. Hara, A. Shimizu, K. Yumimoto, I. Uno, M. Nishikawa, SOLA, 7A, 13 (2011)

20. A. Shimizu, N. Sugimoto, T. Nishizawa, Y. Jin, D. Batdorj, SOLA 13, 205 (2017)

21. Y. Hara, I. Uno, A. Shimizu, N. Sugimoto, I. Matsui, K. Yumimoto, J. Kurokawa, T. Ohara, Z. Liu, SOLA, 7, 121 (2011) 
22. K. Kanatani, et al., Ann. Allergy, Asthma Immunol. 116 (5), 425 (2016)

23. T. Higashi et al., Atmos. Environ. 92, 506 (2014)

24. H. Kobayashi, M. Hayashi, K. Shiraishi, Y. Nakura, T. Enomoto, K. Miura, H. Takahashi, Y. Igarashi, H. Naoe, N. Kaneyasu, T. Nishizawa, N. Sugimoto, Atmos. Environ. 97, 486 (2014)

25. K. Kawai, K. Kai, Y. Jin, N. Sugimoto, D. Batdorj, J. Meteorol. Soc. Jpn. 96 (3), 255 (2018)

26. N. Sugimoto, Y. Hara, A. Shimizu, T. Nishizawa, I. Matsui, M. Nishikawa, Asia-Pacific J. Atmos. Sci. 49 (1), 27 (2013)

27. I. Uno, I., K. Eguchi, K. Yumimoto, T. Takemura, A. Shimizu, M. Uematsu, Z. Liu, Z. Wang, Y. Hara, N. Sugimoto, Nature Geosci. 2, 557 (2009)

28. NAAPS (Naval Research Laboratory (NRL) Aerosol Analysis and Prediction System) https://www.nrlmry.navy.mil/aerosol/ (last Access: December 2018)

29. SPRINTARS (Spectral Radiation-Transport Model for Aerosol Species) https://sprintars.riam.kyushuu.ac.jp/indexe.html (last access: December 2018)

30. NOAA HYSPLIT (Hybrid Single-Particle Lagrangian Integrated Trajectory) Model www page https://ready.arl.noaa.gov/HYSPLIT_traj.php (last access: September 2018)

31. K. Tazaki, R., Wakimoto, Y. Minami, M. Yamamoto, K. Miyata, K. Sato, I. Saji, S.K. Chaerun, G. Zhou, and T. Morishita, Atmos. Environ. 38, 2091 (2004)

32. T. Y. Tanaka, Y. Kurosaki, M. Chiba, T. Matsumura, T. Nagai A. Yamajaki, A. Uchiyama, N. Tsunematsu, and K. Kai, Atmos. Environ., 39, 3901 (2005)

33. N. Sugimoto, I. Matsui, A. Shimizu, I. Uno, K. Asai, T. Endoh, T. Nakajima, Geophys. Res. Lett. 29 (19), 1901 (2002)

34. Z. Wang, X. Pan, I. Uno, J. Li, Z. Wang, X. Chen, P. $\mathrm{Fu}$, T. Yang, H. Kobayashi, A. Shimizu, N. Sugimoto, S. Yamamoto, Atmos. Environ. 159, 83 (2017)

35. Y. Jin, N. Sugimoto, P. Ristori, T. Nishizawa, L. Otero, E. Quel, Appl. Opt. 56 (21), 5990 (2017)

36. Y. Jin, N. Sugimoto, A. Shimizu, T. Nishizawa, K. Kai, K. Kawai, A. Yamazaki, M. Sakurai, H. Willee, J. Appl. Rem. Sens. 12 (4), 042604 (2018)

37. N. Sugimoto, A. Shimizu, T. Nishizawa, Y. Jin, EPJ Web of Conf. 176, 09001 (2018) 